\title{
EFFECT OF POST-WELD HEAT TREATMENT ON THE MICROSTRUCTURE AND MECHANICAL PROPERTIES OF ARC WELDED MEDIUM CARBON STEEL
}

\author{
M. R. Dodo ${ }^{1,}$, T. Ause ${ }^{2}$, M. A. Adamu ${ }^{3}$ and Y. M. Ibrahim ${ }^{4}$ \\ 1,2 Dept. of Metallurgical and Materials EngineEring, Ahmadu Bello Univ. Zaria, Kaduna State. NiGERIA. \\ 3,4 Department of Mechanical Engineering, Ahmadu Bello University Zaria, Kaduna State. NIGERIA. \\ E-mail addresses:1rdmamuda@abu.edu.ng,2ause.terver@yahoo.com,3 adauwa180@yahoo.com, \\ 4 ym.ibrahim@yahoo.com
}

\begin{abstract}
Effect of post-weld heat treatment on the microstructure and mechanical properties of arc welded medium carbon steel was investigated. Medium carbon steel samples were butt- welded by using the shielded metal arc welding technique and, thereafter, heat treated by annealing, normalising and quench hardening in water. The microstructure of the as- welded and post-weld heated samples was characterised by means of optical microscopy while the hardness, toughness and tensile properties of the samples were determined by using Indentec universal hardness testing machine, Izod impact testing machine and Denison tensile testing machine respectively. The results of the optical microscopic test show that fine grains of pearlite in ferrite were obtained in normalized samples and martensite was also observed in quenched samples. On the other hand, mechanical property tests indicated that normalized welded specimens gave good combination of mechanical properties.
\end{abstract}

Key words: Arc welding, weldment, medium carbon steel, welding, post-heat treatment, mechanical properties, microstructure, butt

\section{INTRODUCTION}

Welding is one of the different processes used in the fabrication of metal structure to produce a design or desired shape. It is a process of joining two or more similar or/and dissimilar metals to achieve complete coalescence [1]. There are different types of welding, among others are shielded metal arc welding, submerge arc welding, gas metal arc welding, plasma arc welding, gas tungsten arc welding, projection welding, resistance welding [2].Shielded metal arc welding (SMAW) technique is preferable to the other techniques because of its low cost, flexibility, portability and versatility. Both the equipment and electrodes are low in cost and very simple. SMAW is very flexible in terms of the material thicknesses that can be welded (materials from 1/16" thick to several inches thick can be welded with the same machine and different settings). It is a very portable process because all that's required is a portable power supply (i.e. generator). Finally, it's quite versatile because it can weld many different types of metals, including cast iron, steel, nickel \& aluminum. However, its limitations are that it produces a lot of smoke \& sparks, there is a lot of post-weld clean-up needed if the welded areas are to look presentable, it is a fairly slow welding process and it requires a lot of operator skill to produce consistent quality welds [3]. To fabricate a structure, two factors have to be considered, the cost and how it will fail. Failure of a welded material is likely experienced in the vicinity of the weld [4]. When steel is welded, it is heated; the heated portion has a microstructure that is different from that of the base metal and is called the Heat Affected Zone (HAZ) [4]. During welding, rapid heating and cooling take place which produce severe thermal cycle near weld line region. Conventional welding processes which rely upon the local melting and fusion of materials generates significant residual stress distribution in the weldment. The magnitude of these stresses can under conditions of high restraint, 
approach the yield strength of either the parent or weld materials.

Post weld- heat-treatment is applied to welded steel structures primarily to reduce residual stress and minimize the likelihood of brittle fracture. The benefits of post weld heat- treatment include a significant reduction of tensile residual stress in the weld joint and to lesser extent, tempering of the heat affected zone and the weld metal microstructure. Post weld heat treatment (PWHT) is defined as any heat treatment after welding that often used to improve the properties of a weldment [5]. Post weld heat treatment is intended primarily as a stress relief treatment [1].

The objective of this work is to explore the effect of post-weld heat treatment on the microstructure and mechanical properties of medium carbon steel welded by the shielded metal arc welding technique. The postweld heat treatment investigated include normalizing, annealing and quenching.

\section{MATERIALS AND METHODS}

\subsection{Chemical Composition of Steel and Electrode}

The chemical analysis of the medium carbon steel used was carried out in Dana steel limited, Katsina, by using Mass spectrographic Analyzer (computerized type).

The electrode used was E6013 arc welding electrode. The electrode was of diameter $3.2 \mathrm{~mm}$, commonly referred to as gauge 12 electrodes (Davies, 1945L and $350 \mathrm{~mm}$ length).

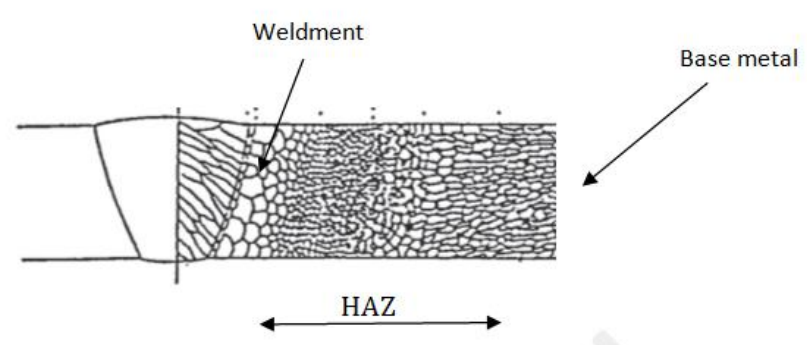

Fig. 1: Schematic illustrations of single V-groove butt joint, showing various zones on the work piece (Source: Merchant, 2015)

\subsection{Welding Operation}

The materials include; medium carbon steel (plain) of $16 \mathrm{~mm}$ in diameter obtained from Dana Steel limited, Katsina state, Nigeria, tap water, silicon carbide grit papers of sizes ranging from 120 to 600 for grinding and 1000 for polishing, 2\% natal etchant, tongs for easy removal of hot samples from the furnace and making punch used for marking gauge length before tensile testing. The equipment used in the experiment includes; Polishing machine CAT. No -IS73-GGG-V; digital metallurgical Microscope, model no. NJF-120A; Indentec Hardness Testing Machine, model no. 8187.5 LKV; Denison tensometer, 500KN maximum load capacity, model no. T42B2; Heat Treatment Furnace, Type ESF $12 / 28$, max temperature $1250^{\circ} \mathrm{C}$; W \& T Avery Izod impact testing machine, capacity $120 \mathrm{ft}$. lb. The medium carbon steel rods were cut into twenty four (24) pieces; 12 of which measured $150 \mathrm{~mm}$ in length for tensile test and the other 12 measured $60 \mathrm{~mm}$ for impact test. After cutting, the medium carbon steel rods were cut width wide to prepare them for butt welding.

Butt welding configuration was adopted. The full penetration butt joint was used. They were therefore welded by simply separating the rods a distance of $1 \mathrm{~mm}$. The welding current and voltage was $160 \mathrm{~A}$ and $100 \mathrm{~V}$ respectively. The current type was AC.

Down-hand welding position was used in welding the rods together. This welding method was such that the rod was laid horizontally on a flat plate with the hand above the line of the weld. After welding, the specimens were allowed to cool on the floor and subsequently a chipping hammer was used to remove the hard slag from the surface of the welds. Machining was carried out in order to level off the weld with the base metal, and lubricant (soluble oil) was applied. The lubricant was carefully used so as not to quench the material.

\subsection{Post- weld heat treatment operations}

Three post-welding heat treatments were adopted for this experiment, namely - full annealing, normalizing and hardening by quenching. The weldments were paired, each pair consisting of three welded specimen for both tensile and impact test. Each pair was then subjected to a particular heat treatment.

Full Annealing heat treatment was made by heating the weldment pair to $900^{\circ} \mathrm{C}$ and holding at this temperature for 30 minutes. Afterwards, they were furnace cooled. On the other hand, normalizing was done on one of the pair in which the specimens were heated to $900^{\circ} \mathrm{C}$ and held for 30 minutes after which they were air cooled. Another pair of specimen was quenched. This involved heating the specimens to $900^{\circ} \mathrm{C}$ and holding at this temperature for 30 minutes. It was then quickly removed and plunged into a bucket of tap water. 
Table 1: chemical analysis of the medium carbon steel used.

\begin{tabular}{lcccccccccc}
\hline Element & $\mathrm{C}$ & $\mathrm{Si}$ & $\mathrm{Mn}$ & $\mathrm{P}$ & $\mathrm{S}$ & $\mathrm{Cr}$ & $\mathrm{Ni}$ & $\mathrm{Mo}$ & $\mathrm{Cu}$ & $\mathrm{Fe}$ \\
\hline Conc. (\%) & 0.32 & 0.16 & 0.68 & 0.014 & 0.029 & 0.06 & 0.11 & 0.02 & 0.21 & 98.447 \\
\hline
\end{tabular}

\subsection{Microstructural examination}

All the specimens (both untreated and heat-treated) were prepared for optical microscopic examination. The specimens were ground on a water lubricated silicon carbide abrasive papers of 180, 240, 320, 400 and 600 grit sizes. Polishing was carried out on $15 \mathrm{~cm}$ rotating discs of a METASERV universal polishing machine with synthetic velvet polishing clothes impregnated with $1 \mu \mathrm{m}$ Alumina paste. The specimens were then etched with $2 \%$ Nital solution using the swabbing method with cotton wool soaked in the etchant.

The microscopic examinations were carried out on M100 optical metallurgical microscope and the microstructures obtained were captured with the aid of in built camera.

\subsection{Mechanical Testing.}

\subsubsection{Tensile Test}

Tensile test was carried out on the $150 \mathrm{~mm}$ specimen. These tests were conducted using a $500 \mathrm{KN}$ Denison Tensile testing Machine. The medium carbon steel specimens were all round cross section. The tests were performed by marking a specimen gauge length of $50 \mathrm{~mm}$ with the aid of a marking punch, then measuring the cross-sectional diameter of the reduced portion. The original cross-sectional diameter was $13 \mathrm{~mm}$. The subsequent steps involved the locking of the specimen in the jaws of the upper and lower cross heads and reading off the value of the applied load from the load cell. The extensor meter attached to the lower, moving crossheads measured the magnitude of the elongations as the load was increased. During the test, the load was increased until fracture occurred. The yield point was also observed from the load cell reading. Both the load on the specimen and its elongation were read off the machine at intervals of $5 \mathrm{KN}$ increase in load. The final load and extension were read off at failure.

\subsubsection{Hardness Test}

The hardness test was performed using the Indentec Universal Hardness Testing Machine. The applied load was $10 \mathrm{~kg}$. the same samples were prepared with smooth and flat surface. The indentations were taken over the weld zones and the heat affected zone. The duration of loading was 10 (ten) seconds. A microscope was swung over the square impression, the diagonals were measured between knife edges, and the reading was taken from a digital counter. The hardness value, obtained by dividing the load by the contact area of the impression, was however, read off digitally from the machine.

\subsubsection{Impact Test}

All the specimens prepared for impact test were subjected to impact test. The test was conducted using the Izod impact testing machine. The dimensions of the test specimen were $60 \mathrm{~mm}$ in length, $13 \mathrm{~mm}$ in diameter, with $2 \mathrm{~mm}$ depth of notch at the middle. The test was performed by making a notch at the middle of the specimen to serve as stress concentrator. The specimen was then clamped to the vice on the machine with the notch facing the pendulum. The pendulum was raised to a certain height and the gauge was set at zero before it was released. The energy absorbed in breaking the specimen was then taken and recorded.

\section{RESULT AND DISCUSSION}

The microstructure developed in the specimens after post-weld heat treatments are described below.

The microstructures of the as-received, weldment and HAZ, annealed, normalized, and quenched weldment and HAZ samples are shown in plate 1 to 3 . The asreceived structure of the sample is shown in plate 1 (a); the structure consists of bands of pearlite in the ferrite matrix. The as-welded weldment structure in plate 1 (b) illustrates as-cast structure and a microstructural in homogenity which is a result of the highest cooling rates. It contains mainly ferrite and colonies of pearlite. The microstructure is heterogeneous due to the temperature and the chemical gradients that generate during the welding process. On the other hand, plate 1(c) represented aswelded HAZ's structure which depicts clearly the microstructures of the zone. It composed of Widmanstatten ferrite, and colonies of pearlite. Solid state phase transformations (grain growth, recrystallization, phase transformations and 
tempering) take place in the HAZ of steel welds. The coarse grained region of the HAZ next to the weld fusion zone consists of grains larger than those in the base metal. It has been reported that there are two phase transformations that take place in the HAZ during cooling. The first is the transformation of high temperature ferrite $(\delta)$ to austenite $(\gamma)$. The second transformation is that of $\gamma$ to $\alpha$ (room temperature ferrite)[13]. However, the annealed weldment sample shows coarse pearlite and ferrite grains (plate 2a) whereas that of the HAZ shows coarse pearlite in large proportion of ferrite (plate $2 \mathrm{~b}$ ). Fined grains of pearlite in ferrite matrix (plate $2 \mathrm{~d}$ ) is observed on the normalized HAZ sample whereas that of weldment shows more refined grains of pearlite and ferrite (plate 2c). The quenched weldment sample structure shows martensite (plate 3a) whereas that of the quenched HAZ shows granular cementite in ferrite matrix (plate3b). The microstructures observed are similar to that observed by Vivek et al. [8].

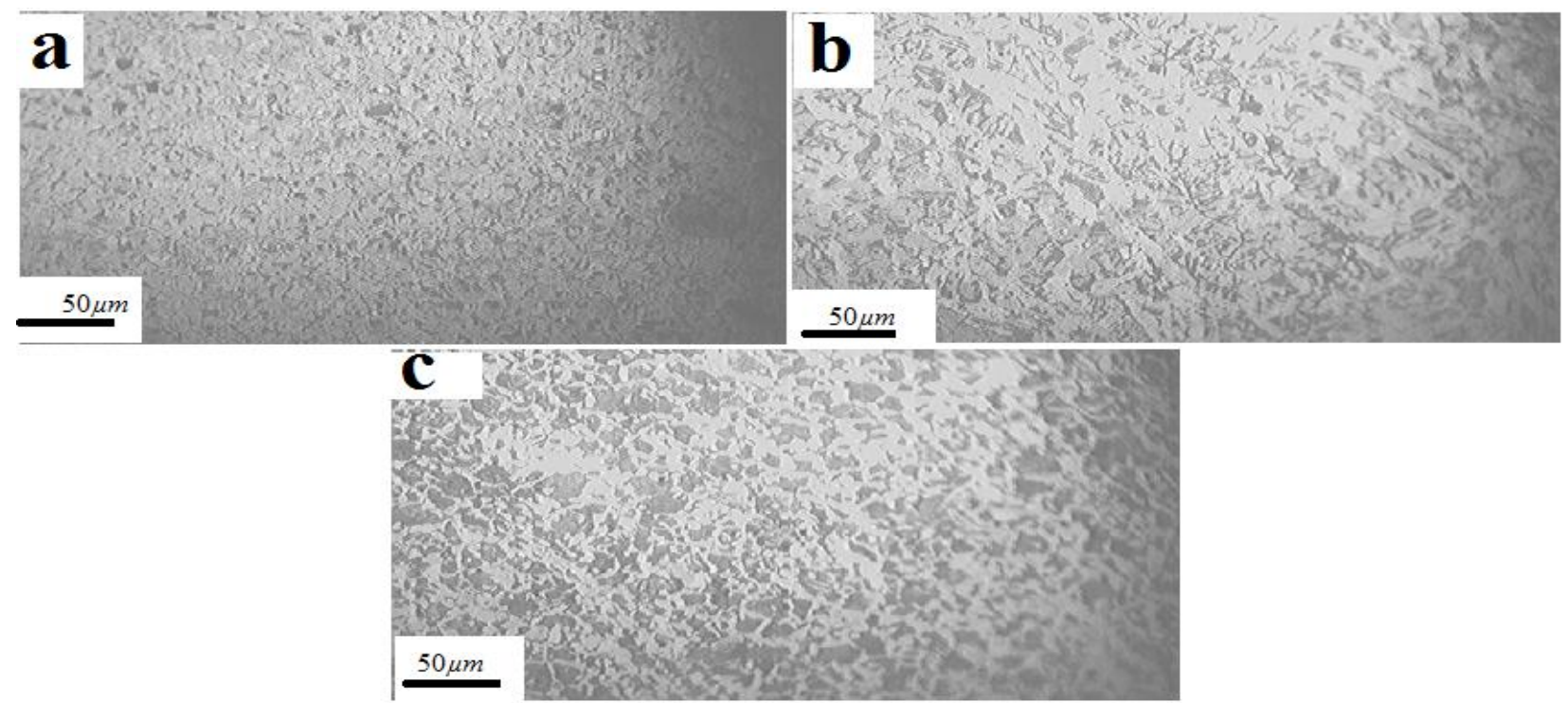

PLATE 1: optical micrograph of (a) as-received medium carbon steel, the structure show pearlite (dark patches) in ferrite matrix (white patches). (b) as-welded weldment, this structure shows as-cast structure of coarse pearlite (dark patches) in ferrite matrix (white patches). (c) as-welded Heat Affected Zone (HAZ), the structure shows coarse pearlite (dark patches) in ferrite matrix (white patches). Etchant: $\%$ Nital, (x200).
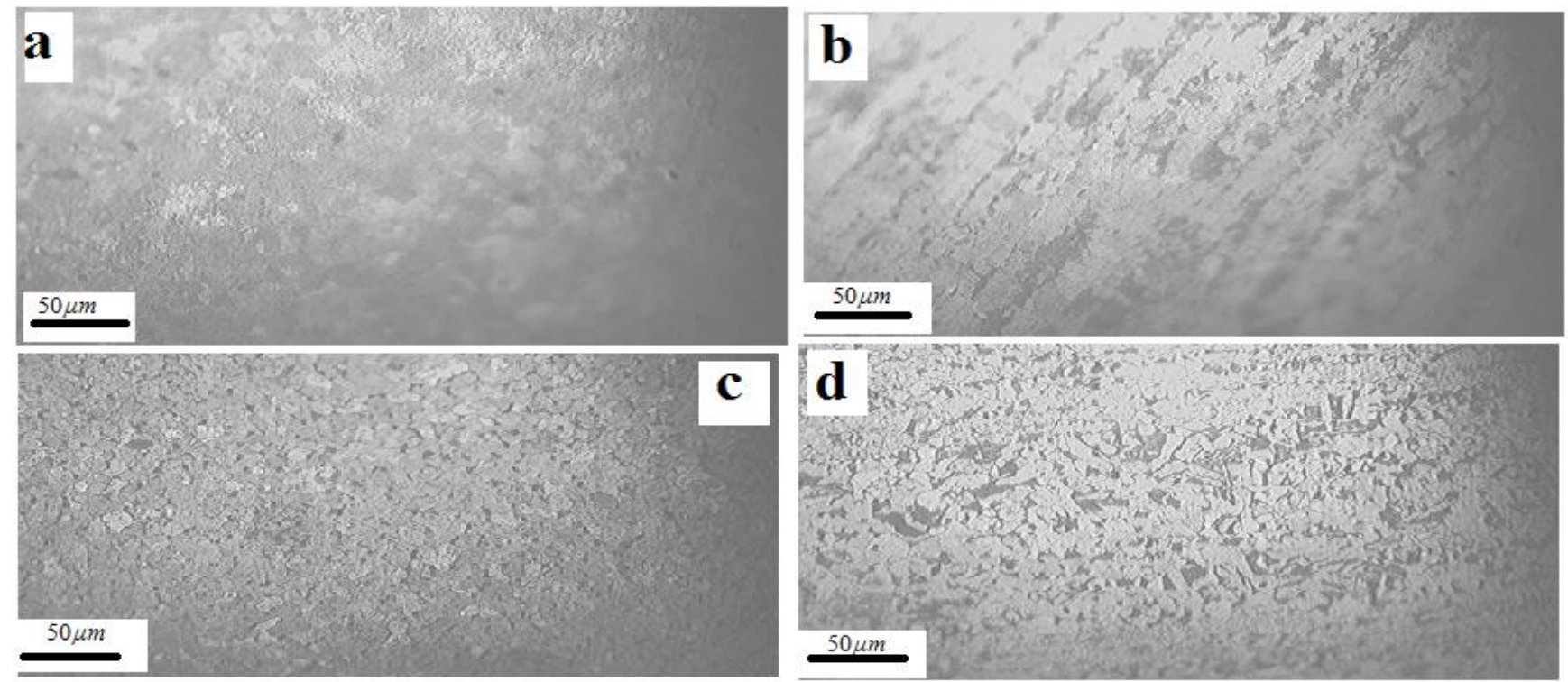

PLATE 2: optical micrograph of (a) annealed weldment sample, this structure shows coarse pearlite and ferrite. (b) annealed (HAZ) sample, this structure shows coarse pearlite in large proportion of ferrite (c) of normalized weldment sample, the structure shows refined grains of pearlite in ferrite matrix. (d) normalized HAZ sample, the structure shows more refined grains of pearlite and ferrite structure. Etchant: $2 \%$ Nital. 

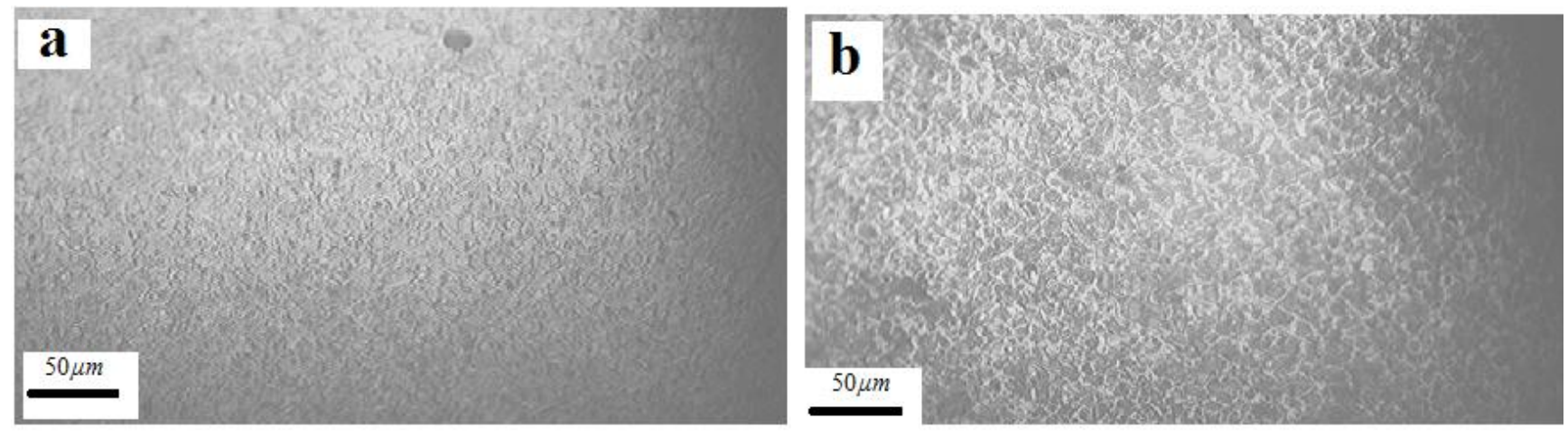

PLATE 3: optical micrograph of (a) quenched weldment sample, the structure shows martensite. (b) Quenched HAZ sample, the structure shows fine grains of equiaxed pearlite in ferrite matrix. Etchant: 2\% Nital, (x200).

Table II: Tensile test parameters for medium carbon steel samples subjected to post welding heat treatment and under as- received and as- welded conditions.

\begin{tabular}{|c|c|c|c|c|c|}
\hline Heat Treatment type & Test zone & $\begin{array}{ll}\text { Yield } & \text { strength } \\
\left(\mathrm{N} / \mathrm{mm}^{2}\right) & \end{array}$ & $\begin{array}{l}\text { Tensile } \\
\text { strength }\left(\mathrm{N} / \mathrm{mm}^{2}\right)\end{array}$ & $\%$ reduction in area & $\%$ Elongation \\
\hline As received & & 290.00 & 313.4 & 40.70 & 12.10 \\
\hline As welded & & - & 230.4 & - & - \\
\hline \multirow[t]{2}{*}{ Annealed } & HAZ & 284.80 & 305.94 & 41.20 & 11.49 \\
\hline & welded & - & 220.70 & - & - \\
\hline \multirow[t]{2}{*}{ Normalized } & HAZ & 324.50 & 360.60 & 34.70 & 11.49 \\
\hline & welded & - & 410.60 & - & - \\
\hline \multirow[t]{2}{*}{ Quenched } & $\mathrm{HAZ}$ & - & 444.76 & - & - \\
\hline & welded & - & 605.87 & - & - \\
\hline
\end{tabular}

Figure 2 shows the tensile strength for the PWHT structures produced by subjecting the welded samples to normalizing, annealing, hardening (quenching by water) heat treatments. The tensile strength of the weldment was observed to be lower compared to asreceived sample. This probably could be due to thermal stresses stored in the weldment during the welding operation this is in agreement with what was reported by Merchant [6].There was a mild decline in the tensile strength value of the weldment after annealing. This could be attributed to the grain growth of ferrite and pearlite grains as observed in plate 2(a). A considerable increase in tensile strength was observed in normalzed and quenched weldment samples, with the quenched samples having the highest value of about $605.87 \mathrm{~N} / \mathrm{mm}^{2}$ when compared to the normalized ones that have about $410 \mathrm{~N} / \mathrm{mm}^{2}$. This rise in tensile strength after normalizing and quenching might have been due to the fact that stored residual stresses in the weldment are relieved and transformation of ferrite and pearlite to martensite respectively. Similarly, tensile strength of the quenched HAZ samples appear to be the highest, followed by normalized and then annealed samples.
This trend shown could be as a result of the different cooling rates exhibited by different post weld heat treatments (normalizing, annealing and quenching). These observations are in line with what Hassan et al. [11] established. Figure 4 shows the hardness profile of post weld heat treated (PWHT) medium carbon steel after subjecting it to welding using SMAW technique.

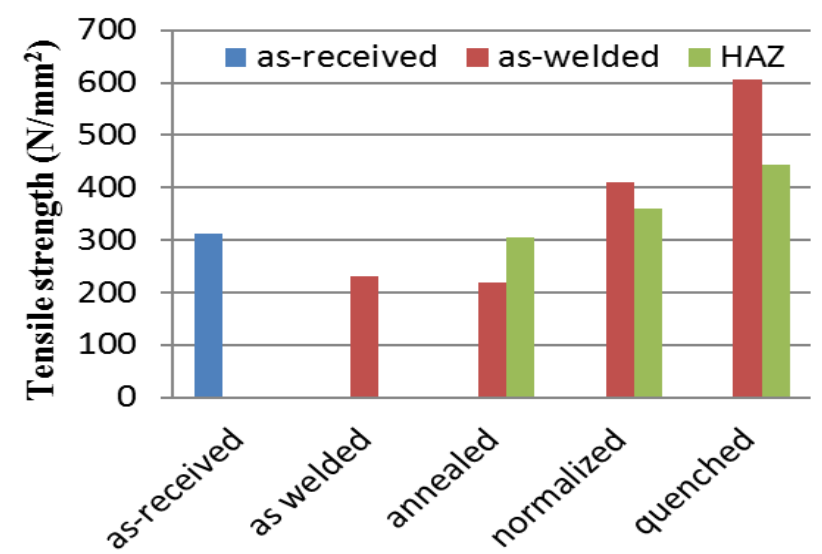

Fig. 2: Effect of post-weld heat treatment on the tensile strength of arc-welded medium carbon steel samples 


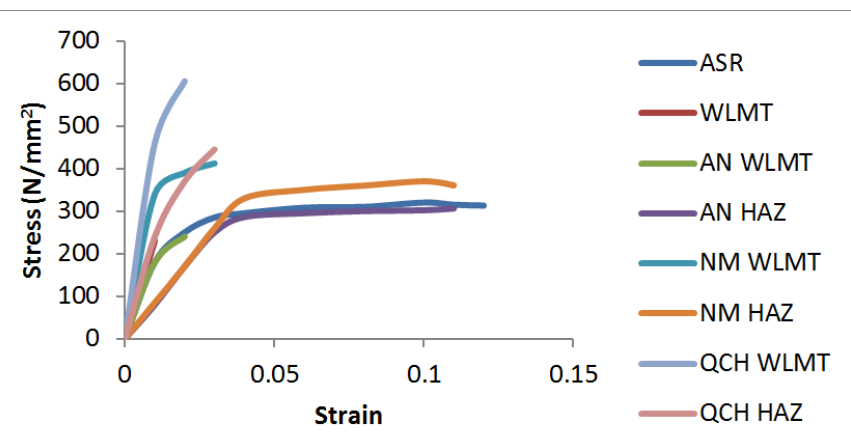

LEGEND: ASR: As-received, WLMT: Weldment, AN: Annealed, NM: Normalized, QCH: Quenched, HAZ: Heat affected zone

Fig. 3: Stress-Strain curve showing effect of post-weld heat treatment on the tensile strength of arc-welded medium carbon steel samples

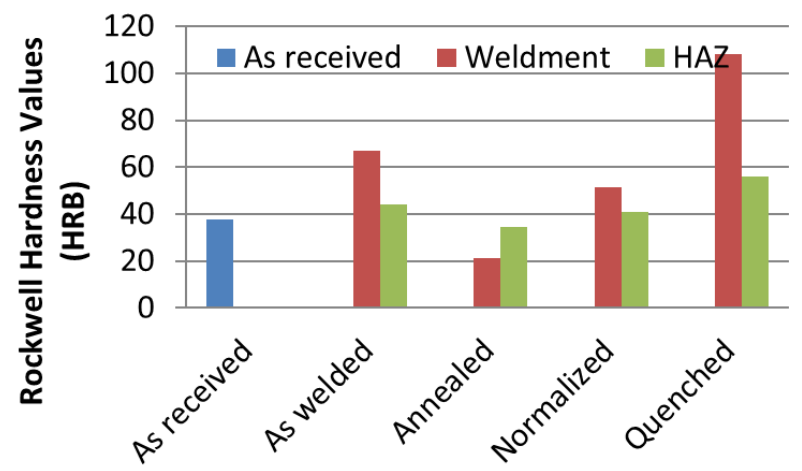

Fig. 4: Effect of post-weld heat treatment on the Hardness profiles of arc-welded medium carbon steel samples

From the results, the weld fusion region in most of the PWHT samples were observed to have displayed higher hardness values with the samples quenched in water attaining a highest value of about 108HRB. The hardness value of the welded portion of the normalized samples were observed to be lower than the as-welded weldment, this might have been due to grains refinement achieved after normalizing. The hardness value of the annealed weldment sample was observed to be slightly lower than the HAZ region, this could be as a result of the grain growth of ferrite and pearlite grains in the weldment (plate 2a, b). However, the quenched weldment and HAZ samples exhibited the highest hardness values of about 108HRB and $56.2 \mathrm{HRB}$ respectively; this could be as a result of the high cooling rates which led to the formation of hard and brittle marten site phase (plate $3 a, b)$.This is in agreement with the report of Rassizadehghani et al., [9].

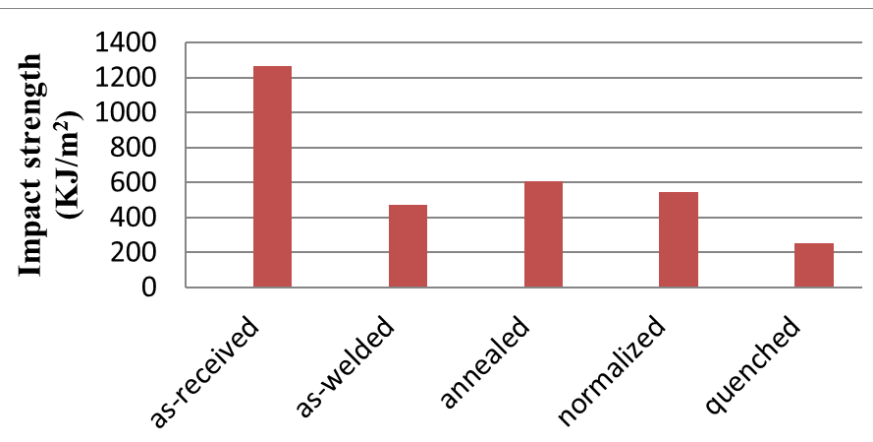

Fig. 5: Effect of post- weld heat treatment on the Impact strength of arc-welded medium carbon steel samples

Figure 5 shows the impact strength (energy absorbed per unit area under the notch) for the PWHT structures produced by subjecting the welded samples to normalizing, annealing, hardening (quenching by water) treatments. The least impact energy absorbed before fracture $\left(252.5 \mathrm{KJ} / \mathrm{m}^{2}\right)$ was obtained from the water quenched specimen. Also, impact strength of $547 \mathrm{KJ} / \mathrm{m}^{2}$ was obtained for normalized specimen while the highest impact energy absorbed was obtained for the annealed sample. The reason could be as a result of the fine grained structure of pearlite and ferrite obtained after normalizing as observed in plate 2. Quenched weldment absorbed lower impact energy than the normalized and annealed samples; this could be connected to the fact that the brittleness of the quenched weldment is higher compared to that of normalized and annealed samples. The trend showed by the impact strength values in relation to the cooling rate of heat treatment processes was similar to that observed by Muhammad [10].

\section{CONCLUSION}

At the end, from the results obtained the following major conclusions are drawn:

$>$ PWHT (especially normalizing) improved mechanical properties of weldment. Hence normalizing heat treatment is recommended as the best heat treatment among the PWHT techniques.

$>$ Tensile strength of the weldment increases after normalizing and quenching operations.

$>$ Full annealing modifies the grain structure and improves ductility and toughness with appreciable reduction in strength and hardness of the weldment as compared to the as-welded weldment.

$>$ Hardness of medium carbon steel increases after welding.

PWHT reduces hardness of weld joint. 
Hardness of HAZ decreases after normalizing heat treatment. It is a little less than that before normalizing.

$>$ Quenching produce a fine grain structure with a very hard, strong and very brittle weldment

\section{REFERENCES}

[1] Hendesen J.G, Metallurgical Dictionary, Rheinhold Publishers Corporations, New York, 2004.

[2] Funk Edward, Hand Book of Welding, Boston Publishers, 2012.

[3] Design and Manufacturing Laboratory. Retrieved from http://www2.mae.ufl.edu/designlab/Lab Assignments/EML2322L-Welding

[4] Vijendra Singh, Physical Metallurgy, Standard Publishers Distributors, NaiSarak, Delhi, 2008.

[5] Houkdcroft P.T, Flux Shielded Arc Welding Process, Cambridge University Press, 2005.

[6] Momoh, I.M., Akinribide, O.J., Ayanleke J., Olowonubi, J., Olorunfemi, G.O., Oshodin, T. Investigating the Mechanical Properties of Post Weld Heat Treated $0.33 \%$ C Low Alloy Steel. International Journal of Science and Technology Volume 2 No. 6, June, 2013 pp433-437.

[7] Ejilah, R.I., Onuh, E.I., Datau, S. and Jatau, J.S.. 'Effect of Post-Weld Heat Treatment on TortionalBehaviour of Low Carbon Steel' Journal of Metallurgy and Materials Engineering. 4(1): 2009. 4-10.
[8] Vivek T., Adarsh P., Zuber M., Chandrashekhar I.B., " Prediction of quench severity of various quench media based on hardness and microstructure studies" International Journal of Innovative Research in Advanced Engineering (IJIRAE) Volume 1 Issue 3. 2013.

[9] Rassizadehghani, J.; Raygan, Sh.; and Askari, M.. Comparison of the quenching capacities of hot salt and oil baths. Metal Sci. Heat Treat. 48(5-6): 193-8. 2006

[10] Muhammmad, T. I.. Evaluation of Polymer Glycerol for Hardening Process in Steel and Cast Iron, Zaria: an M.Sc Seminar, Department of Metallurgical and Materials Engineering, Ahmadu Bello University, 2007.

[11] Hassan, S.B, Balogun, S.O. and V.S. Aigbodion.. "Hardening Characteristics of Medium Carbon Steel Using Fresh Cassava Liquid Extract as Quenchants".Journal of Metallurgy and Materials Engineering. 4(2) 55-61.2009.

[12] Merchant Samir Y. Investigation on effect of welding current and post Weld heat treatment on mechanical properties of Weldment of low carbon steel International Journal of Research in Engineering and Technology 4 (12): pp54-58, 2015.

[13] J. W. Elmer, J. Wong, T. Ressler and T. A. Palmer, 6th International Conference on Trends in Welding Research, Pine Mountain, 6A, April 2002, pp. 15-19. 2002. 